\title{
Estimation of salt intake from spot urine samples in patients with chronic kidney disease
}

\author{
Makoto Ogura*, Ai Kimura, Koki Takane, Masatsugu Nakao, Akihiko Hamaguchi, Hiroyuki Terawaki \\ and Tatsuo Hosoya
}

\begin{abstract}
Background: High salt intake in patients with chronic kidney disease (CKD) may cause high blood pressure and increased albuminuria. Although, the estimation of salt intake is essential, there are no easy methods to estimate real salt intake.
\end{abstract}

Methods: Salt intake was assessed by determining urinary sodium excretion from the collected urine samples. Estimation of salt intake by spot urine was calculated by Tanaka's formula. The correlation between estimated and measured sodium excretion was evaluated by Pearson's correlation coefficients. Performance of equation was estimated by median bias, interquartile range (IQR), proportion of estimates within 30\% deviation of measured sodium excretion $\left(\mathrm{P}_{30}\right)$ and root mean square error (RMSE).The sensitivity and specificity of estimated against measured sodium excretion were separately assessed by receiver-operating characteristic (ROC) curves.

Results: A total of 334 urine samples from 96 patients were examined. Mean age was $58 \pm 16$ years, and estimated glomerular filtration rate (eGFR) was $53 \pm 27 \mathrm{~mL} / \mathrm{min}$. Among these patients, 35 had CKD stage 1 or 2, 39 had stage 3 , and 22 had stage 4 or 5 . Estimated sodium excretion significantly correlated with measured sodium excretion $(R=0.52, P<0.01)$. There was apparent correlation in patients with eGFR $<30 \mathrm{~mL} / \mathrm{min}(R=0.60, P<0.01)$. Moreover, IQR was lower and P30 was higher in patients with eGFR $<30 \mathrm{~mL} / \mathrm{min}$. Estimated sodium excretion had high accuracy to predict measured sodium excretion, especially when the cut-off point was $>170 \mathrm{mEq} /$ day (AUC 0.835).

Conclusions: The present study demonstrated that spot urine can be used to estimate sodium excretion, especially in patients with low eGFR.

Keywords: Chronic kidney disease, Salt intake, Urinary sodium excretion

\section{Background}

Chronic kidney disease (CKD) is characterized by hypertension, which is thought to be predominately salt sensitive [1]. High salt intake in CKD patients may cause high blood pressure, increased albuminuria and increased filtration fraction [2-7]. Salt restriction can result in diminished albuminuria and preservation of renal function [8-10]. The INTERSALT study [11] estimated salt intake by $24 \mathrm{~h}$ urine collection at 52 centers in 32 countries, and showed that the mean daily salt intake was $9.2 \mathrm{~g}$. However, the average estimated salt intake by $24 \mathrm{~h}$ urine collection obtained from 3 Japanese centers was $11.0 \mathrm{~g}$, suggesting that the Japanese have a relatively higher than average salt intake. The major

\footnotetext{
* Correspondence: mogura@jikei.ac.jp

Division of Kidney and Hypertension, Department of Internal Medicine, The Jikei University School of Medicine, 3-19-18, Nishi-shinbashi, Minato-ku, Tokyo 105-8471, Japan
}

methods in current use for assessment salt intake are dietary recall and $24 \mathrm{~h}$ urine sodium excretion measurement. Dietary recall is often inaccurate, and many patients are truly unaware of the amount of sodium they consume. Measurement of $24 \mathrm{~h}$ urine sodium excretion is considered to be reliable, and has been used in many clinical and epidemiological studies, including the INTERSALT study. However, it is relatively difficult to perform because of the necessity of $24 \mathrm{~h}$ urine sampling, and inadequate urine pooling leads to under- or over-estimation of salt intake. The use of a spot urine method, or a brief timed collection, for assessing sodium excretion has previously been examined [12-14]. Tanaka et al. [12] developed a simple method to estimate $24 \mathrm{~h}$ urinary sodium excretion from spot urine specimens collected at any time, using 591 Japanese data items from the INTERSALT study. Estimated sodium 
excretion was significantly correlated with measured sodium excretion using $24 \mathrm{~h}$ urine collection among these populations. There have been few reports about estimated salt intake in patients with a decline in renal function. The purpose of the present study was to evaluate whether the estimation of salt intake from spot urine could predict real salt intake in patients with CKD.

\section{Methods}

A total of 100 CKD subjects were recruited from the outpatient department of The Jikei University Kashiwa Hospital between October 2009 and May 2010. All patients were requested to collect urine for $24 \mathrm{~h}$. Salt intake was assessed by determining urinary sodium excretion from the collected urine samples. Furthermore, spot urine samples were examined on the same day that patients brought their $24 \mathrm{~h}$ urine samples to the hospital. These measurements were performed at least twice during the study period. We also measured urinary creatinine (Cr) excretion using $24 \mathrm{~h}$ urine samples. Data were excluded when urinary $\mathrm{Cr}$ excretion $<1000,>2500 \mathrm{mg} /$ day for male and $<600,>1500 \mathrm{mg} /$ day for female considering inadequate urine collection [15]. Four patients were excluded because of inadequate collection of urine. Estimation of sodium excretion by spot urine was calculated by Tanaka's method, using the following formula [12].

$$
\begin{aligned}
& \text { 24 h Na excretion }(\mathrm{mEq} / \mathrm{d}) \\
& \quad=21.98 \times\{[\mathrm{Na} \mathrm{S} /(\mathrm{Cr} \mathrm{S} \times 10)] \times \operatorname{Pr} . \mathrm{UCr} 24\}^{0.392}
\end{aligned}
$$

$\mathrm{Na} S$ : Na concentration in spot urine $(\mathrm{mEq} / \mathrm{L})$

$\mathrm{Cr} \mathrm{S}: \mathrm{Cr}$ concentration in spot urine $(\mathrm{mg} / \mathrm{dL})$

Pr.UCr24 : predicted value of $24 \mathrm{~h}$ urinary $\mathrm{Cr}$ excretion $(\mathrm{mg} / \mathrm{d})$ $=-2.04 \times$ Age $($ years $)+14.89 \times$ Bodyweight $(\mathrm{kg})$

$+16.14 \times$ Height $(\mathrm{cm})-2244.45$

Briefly, $24 \mathrm{~h}$ sodium excretion $(24 \mathrm{HUNaV})(\mathrm{mEq} /$ day) was estimated by the formula as follows; $21.98 \times \mathrm{XNa}^{0.392}$ $(\mathrm{XNa}=\mathrm{Na}$ concentration in the spot urine / creatinine concentration in the spot urine $\times$ predicted value of $24 \mathrm{~h}$ urinary $\mathrm{Cr}$ excretion (Pr.UCr24)). This formula including constant was obtained using 591 Japanese data items from the INTERSALT study.

Estimated values of urinary sodium excretion calculated using spot urine were compared to sodium excretion assessed by $24 \mathrm{~h}$ urine samples. The correlation between estimated and measured sodium excretion was evaluated by univariate analysis. The values of salt intake were calculated from urinary sodium excretion by standard method ( $1 \mathrm{mEq}$ of sodium $=58.5 \mathrm{mg}$ of $\mathrm{NaCl}$ ). Correlations between estimated and measured sodium excretion were evaluated by Pearson's correlation coefficients. The median difference between measured and estimated sodium excretion was used to calculate the bias. Precision of the estimates was expressed by interquartile range (IQR). Accuracy was measured as the proportion of estimates within
$30 \%$ deviation of measured sodium excretion $\left(\mathrm{P}_{30}\right)$. Accuracy was also expressed in terms of the root mean square error (RMSE). The Bland-Altman Plot was used to estimate the bias and limits of agreement between measurements by the two methods. To analyze the sensitivity and specificity of estimated sodium excretion in relationship to measured sodium excretion, receiver-operating characteristic (ROC) curves were generated, including area under the curve (AUC) and their 95\% confidence intervals (CI). The sensitivity and specificity of estimated against measured sodium excretion were separately assessed by two cut-off points ( $>170$ and $>100 \mathrm{mEq} /$ day, respectively).

The protocol was in conformity with institutional ethical guidelines (The Ethical Committee of The JIkei university school of medicine) and informed consent was obtained from each participant. Data were analyzed by using SPSS 17.0 (SPSS Inc, Chicago, IL), Bland-Altman with MedCalc software (version 12.1.4.0; Mariakerke Belgium). The $P$ values reported are 2-sided and were taken to be statistically significant at 0.05 .

\section{Results}

Table 1 shows the characteristics of patients. Mean age was $58 \pm 16$ years and $49 \%$ of the patients were men. Mean serum $\mathrm{Cr}$ was $1.4 \pm 1.0 \mathrm{mg} / \mathrm{dL}$ and estimated glomerular filtration rate (eGFR) was $53 \pm 27 \mathrm{~mL} / \mathrm{min}$. Among these patients, 35 had stage 1 or 2 CKD (36.5\%), 39 had stage 3 CKD (40.6\%), and 22 had stage 5 CDK (22.9\%). Mean urinary protein excretion was $1.2 \pm 1.4 \mathrm{~g} /$ day.

A total of 334 samples from 96 patients were examined. Figure 1 shows the correlation between estimated sodium excretion by spot urine and measured sodium excretion assessed by $24 \mathrm{~h}$ urine sampling. Estimated sodium excretion significantly correlated with measured sodium excretion $(\mathrm{R}=0.52, \mathrm{P}<0.01)$. Figure 2 demonstrates the correlation between estimated and measured

Table 1 Clinical characteristics

\begin{tabular}{ll}
\hline Characteristics & $\mathbf{n}=\mathbf{9 6}$ \\
\hline Age (years) & $58 \pm 16$ \\
Gender (male, \%) & $47(49)$ \\
Cr (mg/dL) & $1.4 \pm 1.0$ \\
eGFR (mL/min) & $53 \pm 27$ \\
CKD stage (n, \%) & \\
stage 1,2 & $35(36.5)$ \\
stage 3 & $39(40.6)$ \\
stage 4,5 & $22(22.9)$ \\
UPR (g/d) & $1.2 \pm 1.4$ \\
Urine volume (mL/d) & $1889 \pm 547$ \\
\hline
\end{tabular}

eGFR: estimated glomerular filtration rate, UPR: urinary protein excretion. 


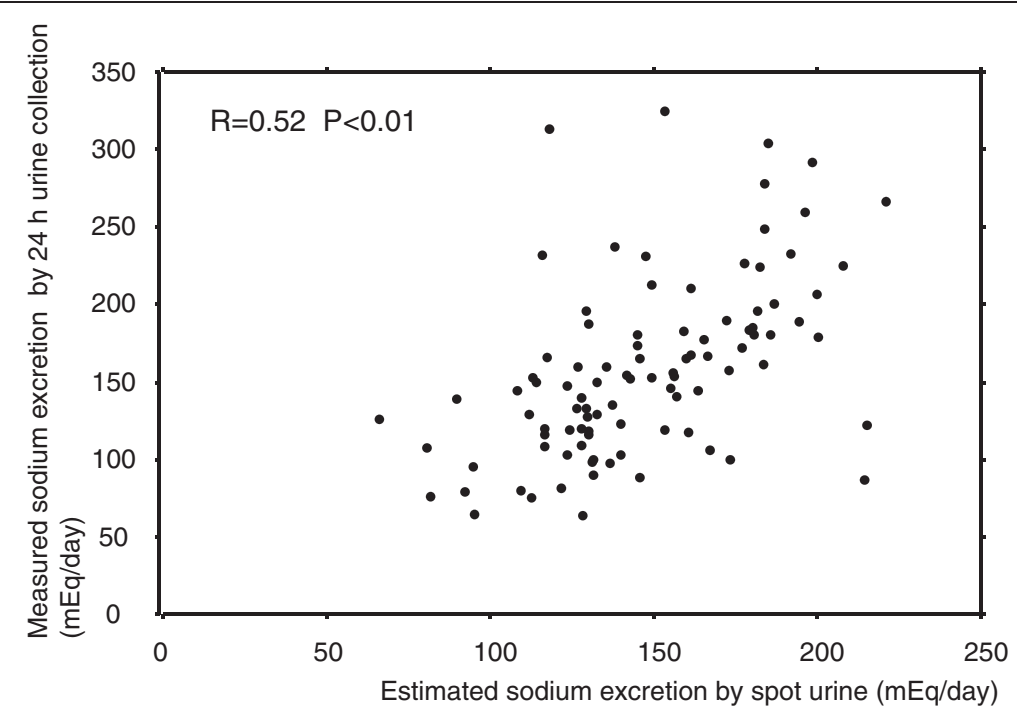

Figure 1 Correlation between estimated sodium excretion by spot urine and measured sodium excretion assessed by $24 \mathrm{~h}$ urinary samples. Estimated sodium excretion significantly correlated with measured sodium excretion $(R=0.52, P<0.01)$.

sodium excretion categorized by eGFR. Significant correlations were recognized between estimated and measured sodium excretion in patients with eGFR $>60$ and $30-60 \mathrm{~mL} / \mathrm{min}(\mathrm{R}=0.52, \mathrm{P}<0.01$ and $\mathrm{R}=0.47, \mathrm{P}<0.01$, respectively). There was apparent correlation in patients with eGFR $<30 \mathrm{~mL} / \min (\mathrm{R}=0.60, \mathrm{P}<0.01)$.
Figure 3 shows Bland-Altman analysis of the differences between estimated and measured sodium excretion compared to the average sodium excretion by the two methods. The mean difference was -10.9 (central line). A total of $94 \%$ (90 of 96) of the values lie within 1.96 SDs of the mean (outer lines).

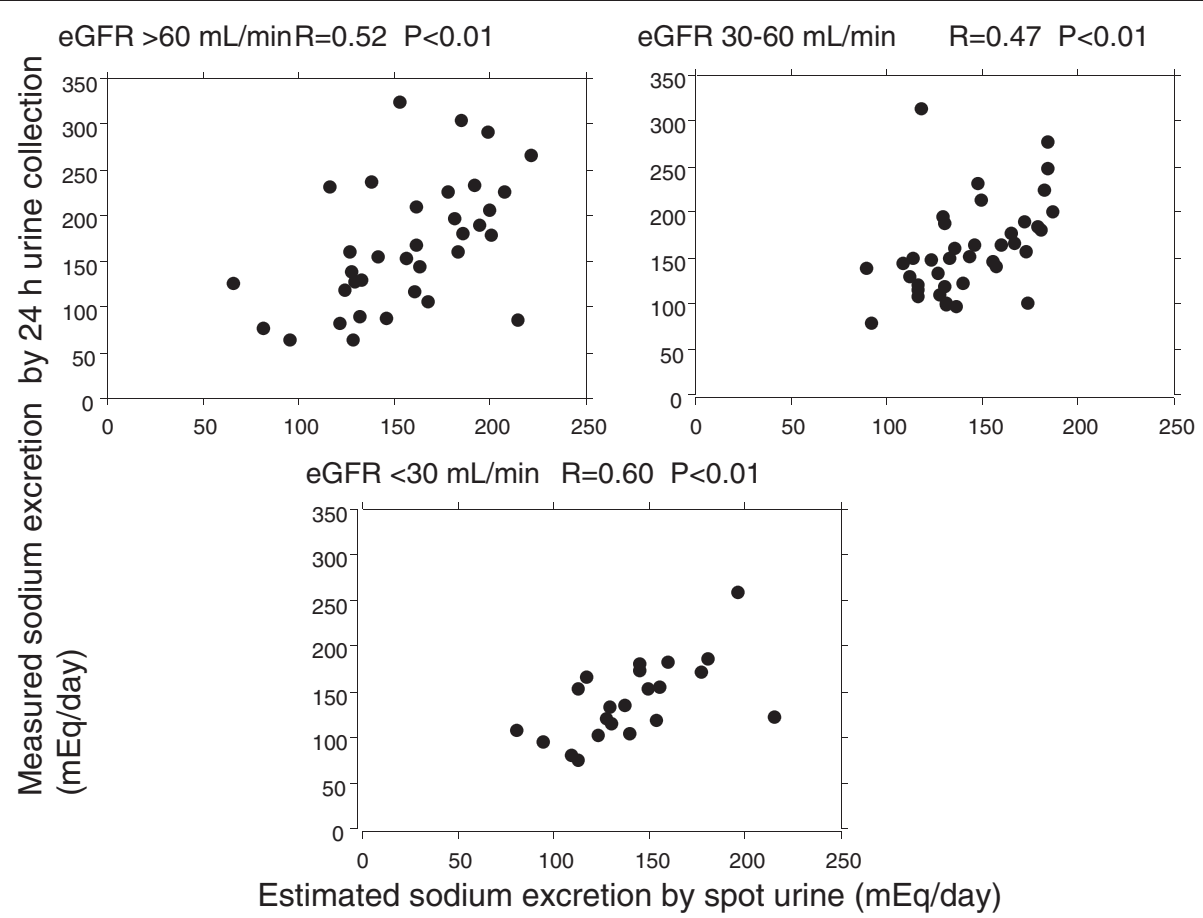

Figure 2 Correlation between estimated sodium excretion and measured sodium excretion categorized by eGFR. Significant correlations were recognized between estimated and measured sodium excretion in patients with eGFR $>60$ and $30-60 \mathrm{~mL} / \mathrm{min}(\mathrm{R}=0.52, \mathrm{P}<0.01$ and $R=0.47, P<0.01$, respectively). There was apparent correlation in patients with eGFR $<30 \mathrm{~mL} / \mathrm{min}(R=0.60, P<0.01)$. 


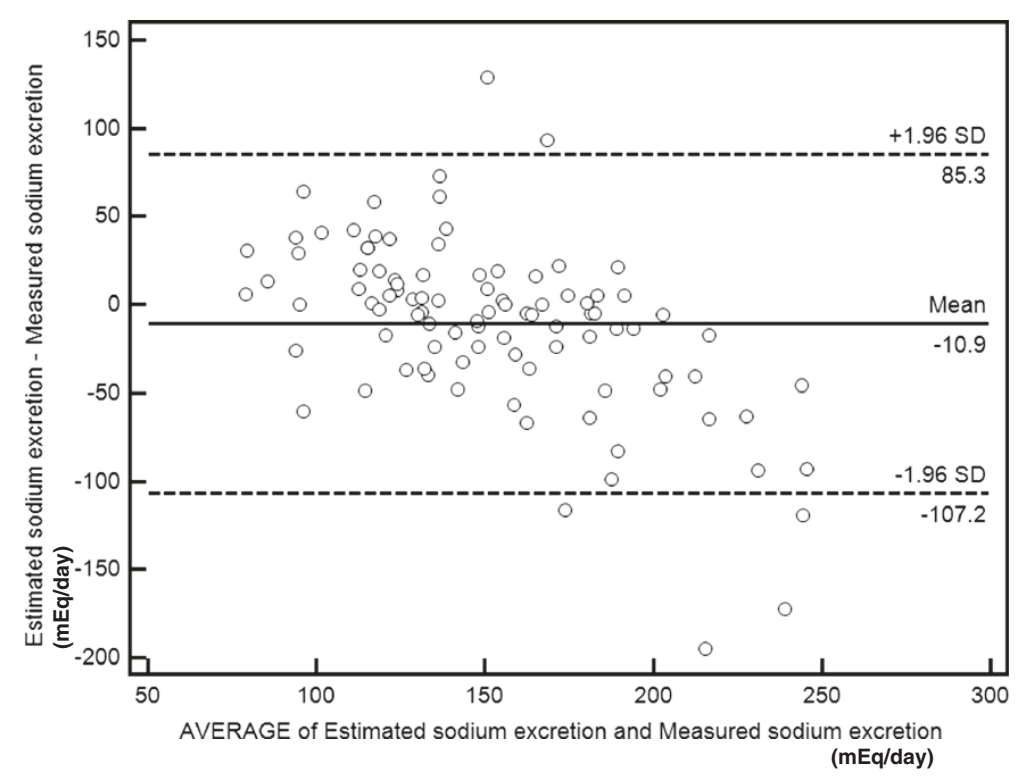

Figure 3 Bland-Altman analysis of the differences between estimated and measured sodium excretion compared to the average sodium excretion by the two methods. The mean difference was -10.9 (central line). A total of $94 \%$ (90 of 96) of the values lie within 1.96 SDs of the mean (outer lines).

Table 2 demonstrated performance of urinary sodium estimating equation in patients with CKD. Median bias was 4.5 and percentage bias was $2.7 \%$. IQR, an indicator of precision, was $53 \mathrm{mEq} /$ day. RMSE and P30, an indicator of accuracy, were $50 \mathrm{mEq} /$ day and $70 \%$, respectively in overall patients. For each of the eGFR equations, the dataset was split into 3 groups: eGFR $<30,30-60$, and $>60 \mathrm{~mL} / \mathrm{min}$. Median bias and IQR were lower in patients with eGFR $<30 \mathrm{~mL} / \mathrm{min}$. Moreover, RMSE was lower and P30 was higher in patients at lower levels of eGFR (Table 2, Figure 4).

Finally, AUC values of estimated sodium excretion for predicting measured sodium excretion were examined by ROC curves. As shown in Figure 5, the AUC values were 0.835 and 0.719 , respectively, when the cut-off point was $>170 \mathrm{mEq} /$ day and $>100 \mathrm{mEq} /$ day. Estimated sodium excretion had high accuracy to predict measured sodium excretion, especially when the cut-off point was $>170 \mathrm{mEq} /$ day.

\section{Discussions}

The present study indicated that estimated sodium excretion from spot urine collected from CKD patients had adequate value for prediction of measured sodium excretion from $24 \mathrm{~h}$ urine collection. The use of a spot urine method or another brief timed collection for assessment of sodium excretion has previously been examined [12-14]. Kamata et al. [13] predicted 24 h sodium excretion using overnight urine by pipe-sampling method. Pr.UCr24 was estimated from lean body mass. Sodium excretion in nighttime urine has been reported to be relatively close agreement with the value determined in $24 \mathrm{~h}$ urine collection. Kawasaki et al. [14] estimated urinary sodium excretion, using $\mathrm{Na} / \mathrm{Cr}$ concentrations in the second urine sample collected after waking. An estimate of Pr.UCr24 can be calculated from a formula height, body weight and age. However, its clinical use may be limited because second urine sampling must be performed after waking and before breakfast.

Table 2 Performance of urinary sodium estimating equation

\begin{tabular}{|c|c|c|c|c|c|c|}
\hline eGFR & $\mathrm{n}$ & Median bias & Median percentage bias & IQR & RMSE & P30 \\
\hline $\mathrm{mL} / \mathrm{min}$ & & $(95 \% \mathrm{Cl})$ & $\%$ & $\overline{\mathrm{mEq} / \mathrm{day}}$ & $\overline{\mathrm{mEq} / \mathrm{day}}$ & $\%$ \\
\hline$\overline{e G F R}<30$ & 22 & $0.0(-14.2-24.1)$ & 0.0 & 46 & 34 & 82 \\
\hline eGFR 30-60 & 39 & $9.0(-1.0-19.4)$ & 5.9 & 48 & 48 & 72 \\
\hline eGFR $>60$ & 35 & $-2.0(-5.8-16.3)$ & -1.3 & 67 & 60 & 60 \\
\hline Overall & 96 & $4.5(-2.1-12.2)$ & 2.7 & 53 & 50 & 70 \\
\hline
\end{tabular}

eGFR: estimated glomerular filtration rate, IQR: interquartile range, RMSE: root mean square error, P30: percentage of estimated sodium intake within $30 \%$ of measured sodium intake. 


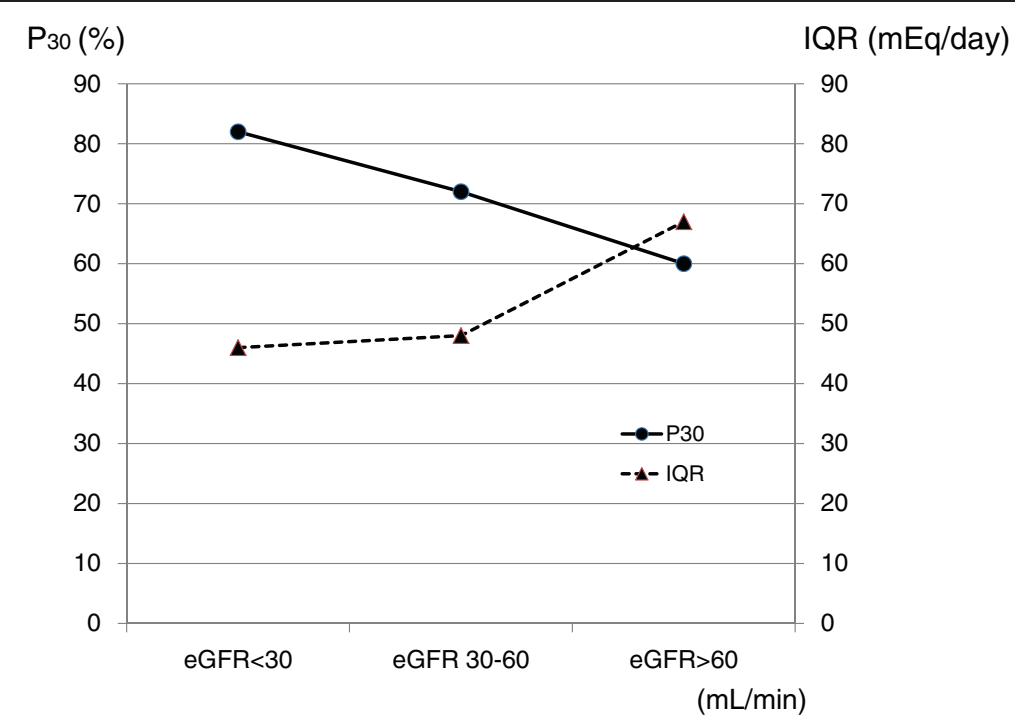

Figure 4 Accuracy and precision of estimates expressed as P30 and IQR categorized by eGFR. Highest accuracy within 30\% and lowest precision were found for samples with an eGFR $<30 \mathrm{~mL} / \mathrm{min}$. P30: percentage of estimated sodium intake within $30 \%$ of measured sodium intake, IQR: interquartile range.

Estimation of salt intake using a spot urine sample collected at any time would be much easier to perform. Unfortunately, the spot urine $\mathrm{Na} / \mathrm{Cr}$ ratio has inherent limitations in estimating $24 \mathrm{~h}$ sodium excretion because sodium excretion varies considerably from hour to hour. And, the accuracy of predicting $24 \mathrm{~h}$ sodium excretion is altered by interindividual differences in $24 \mathrm{~h}$ creatinine excretion. Tanaka et al. [12] reported a simple method that can be used to estimate $24 \mathrm{~h}$ urinary sodium excretion from spot urine specimens that are collected at any time using 591 Japanese data items from the INTERSALT study. Estimated sodium excretion calculated by the formulas shown in Table 1 significantly correlated with measured sodium excretion using $24 \mathrm{~h}$ urine collection among the population $(\mathrm{R}=0.54, \mathrm{P}<0.01)$. They also performed an additional validity examination using external 513 people who did not participate in the INTERSALT study. Consequently, they reported that the difference between measured and estimated values was larger in quintile groups with a smaller amount of
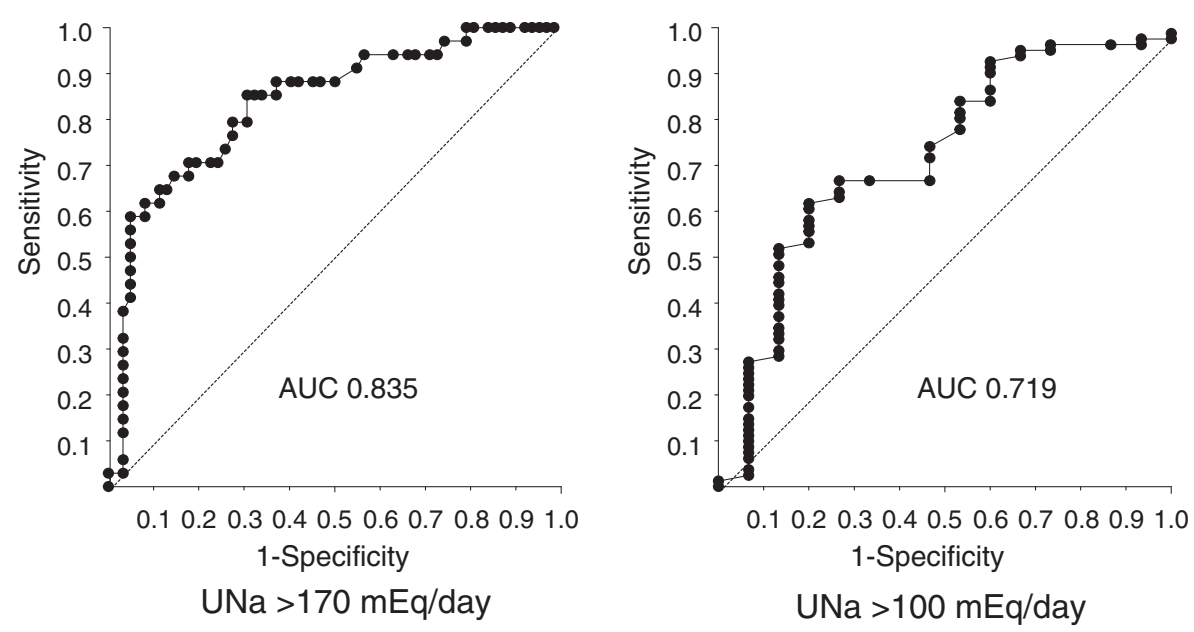

Figure 5 ROC curves, including area under the curve (AUC). The sensitivity and specificity of estimated sodium excretion against measured sodium excretion was separately assessed by two cut-off points (>170 and $>100 \mathrm{mEq} /$ day, respectively). Estimated sodium excretion had high accuracy to predict measured sodium excretion using AUC, especially when the cut-off point was $>170 \mathrm{mEq} /$ day (AUC 0.835). UNa: urinary sodium excretion. 
sodium excretion. They mentioned that the method was nonetheless considered to be useful to estimate sodium excretion of subjects with relatively high salt intake, because the differences were smaller in the quintile groups with larger amounts of sodium excretion.

In the present data, using Tanaka's method, estimated sodium excretion significantly correlated with measured sodium excretion $(R=0.52, P<0.01)$. Such correlation coefficient was nearly the same as Tanaka's data. Patients with a low eGFR (stage 4 and 5 CKD) had a relatively stronger correlation $(\mathrm{R}=0.60, \mathrm{P}<0.01)$ than patients with a moderate to high eGFR. Moreover, the assessments of performance for urinary sodium equation demonstrated that median bias and IQR were lower in patients with eGFR $<30 \mathrm{~mL} / \mathrm{min}$. Accuracy, which were estimated by RMSE and P30, were higher in patients at lower levels of eGFR. These results indicated Tanaka's method had higher predictive value especially in low eGFR patients with CKD.

Sodium excretion exhibits a diurnal rhythm. In the general population, sodium excretion during the nighttime has been reported to be $20 \%$ lower than during the daytime [16,17]. Moreover, sodium excretion was reported to be higher in the afternoon than in the morning [18]. Several studies have demonstrated that the $24 \mathrm{~h}$ $\mathrm{Na} / \mathrm{Cr}$ ratio was markedly correlated with the spot urine $\mathrm{Na} / \mathrm{Cr}$ ratio obtained in the late afternoon, not in the morning $[19,20]$. In the present study, most of the spot urine samples were collected in the morning. The moderate correlation between measured and estimated sodium excretion $(R=0.52)$ was probably due to the difference of the time to submit spot urine. Fukuda et al. [21] investigated the impact of renal function on the night/day ratio of blood pressure and urinary water and electrolyte excretion. They demonstrated in patients with glomerulopathy that as renal function deteriorated, nocturnal blood pressure elevated and urinary excretion rates of sodium and protein were enhanced during the night. The present study revealed that estimated sodium excretion tended to have a higher accuracy to assess measured (real) salt intake in patients with a low eGFR. Considering these findings, the low eGFR could have muted the diurnal fluctuation of sodium excretion, and stabilized the predicted value.

Finally, the sensitivity and specificity of estimated sodium excretion were analyzed in relationship to measured sodium excretion with two cut-off points $(>170$ and $>100 \mathrm{mEq} /$ day). International recommendations suggest that the salt intake of the general population should be less than 5-6 g $(100 \mathrm{mEq}) /$ day $[22,23]$. On the other hand, while salt intake in Japan is decreasing, it is still high, at about $11 \mathrm{~g} /$ day. Kuriyama et al reported reduction in salt intake from 11-14 $\mathrm{g} /$ day to $7-8 \mathrm{~g} /$ day led to a significant decrease in daily protein excretion in
51 Japanese CKD patients [10]. Swift et al reported that reducing salt intake from $170 \mathrm{mEq} /$ gay to $89 \mathrm{mEq} /$ day reduced blood pressure and urine protein excretion in black hypertensives [24]. Considering these findings, the two cut-off points were set at $>170 \mathrm{mEq}(10 \mathrm{~g}) /$ day and $>100 \mathrm{mEq}(6 \mathrm{~g}) /$ day. Estimated sodium excretion using spot urine had high accuracy to predict measured sodium excretion when the cut-off point was $>170 \mathrm{mEq} /$ day (AUC: 0.835 ). These results agreed with Tanaka's assessment that the equation was considered to be useful to estimate sodium excretion of subjects with relatively high salt intake.

There were some limitations in the present study. The number of patients recruited was relatively small. Moreover, number of patients with a low eGFR (stage 4 and 5 CKD) was smaller than patients with a moderate or high eGFR (stage 1 to 3 CKD). Further studies with larger numbers of patients allocated equally by eGFR may be needed to clarify these issues.

\section{Conclusions}

The present study demonstrated that salt intake could be estimated by spot urine samples, especially in CKD patients with relatively high salt intake and with a low eGFR. Although measurement of $24 \mathrm{~h}$ urine sodium excretion is considered the gold standard, assessment of salt intake in spot urine samples could be applied, in part, for management of patients with CKD.

\section{Abbreviations}

CKD: Chronic Kidney Disease; eGFR: Estimated Glomerular Filtration Rate: Cr: Creatinine; Pr.UCr24: 24 h Urinary Cr Excretion; IQR: Inter quartile range; $\mathrm{P}_{30}$ : Proportion of estimates within $30 \%$ deviation of measured sodium excretion; RMSE: Root mean square error; ROC: Receiver-Operating Characteristic; AUC: Area Under the Curve; Cl: Confidence Intervals.

\section{Competing interests}

All the authors declare no competing interests.

\section{Authors' contributions}

$\mathrm{MO}$ analyzed the data in this study, and all authors interpreted the data. All authors contributed substantially to the writing of this manuscript and read and approved the final manuscript

\section{Acknowledgements}

None

Received: 21 August 2011 Accepted: 21 May 2012

Published: 8 June 2012

\section{References}

1. Weir MR, Fink JC: Salt Intake and Progression of Chronic Kidney Disease: An Overlooked Modifiable Exposure? A Commentary. Am J Kid Dis 2005, 45:176-188.

2. Jones-Burton C, Mishra SI, Fink JC, Brown J, Gossa W, Bakris GL, Weir MR An in-depth review of the evidence linking dietary salt intake and progression of chronic kidney disease. Am J Nephrol 2006, 26:268-275.

3. Bakris GL, Smith A: Effects of sodium intake on albumin excretion in patients with diabetic nephropathy treated with long-acting calcium antagonists. Ann Intern Med 1996, 125:201-204. 
4. Heeg JE, de Jong PE, van der Hem GK, de Zeeuw D: Efficacy and variability of the antiproteinuric effect of ACE inhibition by lisinopril. Kidney Int 1989, 36:272-279

5. Imanishi M, Yoshioka K, Okumura M, Konishi Y, Okada N, Morikawa T, Sato T, Tanaka S, Fujii S: Sodium sensitivity related to albuminuria appearing before hypertension in type 2 diabetic patients. Diabetes Care 2001, 24:111-116.

6. Parmer RJ, Stone RA, Cervenka JH: Renal hemodynamics in essential hypertension. Racial differences in response to changes in dietary sodium. Hypertension 1994, 24:752-757.

7. Schiffl H, Kuchle C, Lang S: Dietary salt, intracellular ion homeostasis and hypertension secondary to early-stage kidney disease. Miner Electrolyte Metab 1996, 22:178-181.

8. Cianciaruso B, Bellizzi V, Minutolo R, Colucci G, Bisesti V, Russo D, Conte G, De Nicola L: Renal adaptation to dietary sodium restriction in moderate renal failure resulting from chronic glomerular disease. J Am Soc Nephrol 1996, 7:306-313

9. Cianciaruso B, Bellizzi V, Minutolo R, Tavera A, Capuano A, Conte G, De Nicola L: Salt intake and renal outcome in patients with progressive renal disease. Miner Electrolyte Metab 1998, 24:296-301.

10. Kuriyama S, Tomonari H, Ohtsuka Y, Yamagishi H, Ohkido I, Hosoya T: Salt intake and the progression of chronic renal diseases (in Japanese). Nippon Jinzo Gakkai Shi 2003, 45:751-758.

11. Intersalt Cooperative Research Group: INTERSALT: an international study of electrolyte excretion and blood pressure: results for $24 \mathrm{~h}$ urinary sodium and potassium excretion. Br Med J 1988, 297:319-328.

12. Tanaka T, Okamura T, Miura K, Kadowaki T, Ueshima H, Nakagawa $H_{\text {, }}$ Hashimoto T: A simple method to estimate populational 24-h urinary sodium and potassium excretion using a casual urine specimen. $J$ Hum Hypertens 2002, 16:97-103.

13. Kamata K, Tochikubo O: Estimation of $\mathbf{2 4} \mathrm{h}$ urinary sodium excretion using lean body mass and overnight urine collected by a pipe-sampling method. J Hypertens 2002, 20:2191-2197.

14. Kawasaki T, Itoh K, Uezono K, Sasaki H: A simple method for estimating $24 \mathrm{~h}$ urinary sodium and potassium excretion from second morning voiding urine specimen in adults. Clin Exp Pharmacol Physiol 1993, 20:7-14.

15. Kawasaki T, Uezono K, Ueno M, Kikkawa K, Komuro T, Nakamuta S, Kawazoe $\mathrm{N}$, Muratani $\mathrm{H}$, Omae T: Studies of urinary creatinine excretion in clinically healthy subjects (1) Influence of age, sex, exercise and amount of salt intake on urinary creatinine excretion and its circadian rhythm. $J$ Health Sci 1984, 6:1-8.

16. Kawano Y, Kawasaki T, Kawazoe N, Abe I, Uezono K, Ueno M, Fukiyama K, Omae T: Circadian variations of urinary dopamine, norepinephrine, epinephrine and sodium in normotensive and hypertensive subjects. Nephron 1990, 55:277-282.

17. Staessen J, Broughton PM, Fletcher AE, Markowe HL, Marmot MG, Rose G, Semmence A, Shipley MJ, Bulpitt CJ: The assessment of the relationship between blood pressure and sodium intake using whole-day, daytime and overnight urine collections. J Hypertens 1991, 9:1035-1040

18. Kawasaki T, Nakamuta S, Fukiyama K, Omae T: Determination of urinary excretions of aldosterone and sodium by short-term collections of urine in healthy men. Jpn Circ J 1978, 43:621-626.

19. Kawasaki T, Uezono K, Utsunomiya H, Imamura K, Kikkawa K, Ueno M, Fujishima M: Studies on estimation of 24-hour urinary sodium excretion from predicted creatinine excretion and fractional urine sodium/ creatinine ratio. $J$ Health Sci 1986, 8:57-63.

20. Mann SJ, Gerber LM: Estimation of 24-hour sodium excretion from spot urine samples. J Clin Hypertens 2010, 12:174-180.

21. Fukuda M, Munemura M, Usami T, Nakao N, Takeuchi O, Kamiya Y, Yoshida A, Kimura G: Nocturnal blood pressure is elevated with natriuresis and proteinuria as renal function deteriorates in nephropathy. Kidney Int 2004, 65:621-625.

22. WHO Regional Office for Europe: Nutrition, Food Security Programme Food based dietary guidelines in the WHO European region. Copenhagen: Denmark; 2003

23. Whelton PK, He J, Appel LJ, Cutler JA, Havas S, Kotchen TA, Roccella EJ, Stout R, Vallbona C, Winston MC, Karimbakas J, National High Blood Pressure Education Program Coordinating Committee: Primary prevention of hypertension: clinical and public health advisory from The National High Blood Pressure Education Program. JAMA 2002, 288:1882-1888.
24. Swift PA, Markandu ND, Sagnella GA, He FJ, MacGregor GA: Modest salt reduction reduces blood pressure and urine protein excretion in black hypertensives A randomized control trial. Hypertension 2005, 46:308-312.

doi:10.1186/1471-2369-13-36

Cite this article as: Ogura et al.: Estimation of salt intake from spot urine samples in patients with chronic kidney disease. BMC Nephrology 2012 13:36.

\section{Submit your next manuscript to BioMed Central and take full advantage of:}

- Convenient online submission

- Thorough peer review

- No space constraints or color figure charges

- Immediate publication on acceptance

- Inclusion in PubMed, CAS, Scopus and Google Scholar

- Research which is freely available for redistribution 